\title{
Middle East Respiratory Syndrome Coronavirus
}

\author{
Batool Sharifi-Mood ${ }^{1, *}$ \\ ${ }^{1}$ Infectious Diseases and Tropical Medicine Research Center, Zahedan University of Medical Sciences, Zahedan, IR Iran \\ ${ }^{*}$ Corresponding author: Batool Sharifi-Mood, Infectious Diseases and Tropical Medicine Research Center, Boo-Ali Hospital, Zahedan University of Medical Sciences, Zahedan, IR Iran. \\ Tel: +98-5413228101, Fax: +98-5413236722, E-mail: batoolsharifimood@yahoo.com \\ Received: May 28, 2014; Accepted: January 18, 2015
}

Keywords:MERS-CoV; Pevention; Standard Precautions

Coronaviruses are a large family of viruses including the common cold and severe acute respiratory syndrome (SARS) viruses that are known to cause disease in humans and animals. Middle Eastern respiratory syndrome coronavirus (MERS-CoV) is a new strain that had not previously been observed in animals and humans and it seems that camels are a reservoir for this infection (1-4). It is genetically distinct from the severe acute respiratory syndrome coronavirus (SARS-CoV), which has emerged as a pandemic in the last decade and appears to behave differently (1). The MERS-CoV was reported to cause human infection during September 2012. Since March 2014, the number of cases with MERS-CoV has increased. In May 2014, 536 laboratory confirmed cases were reported by the World Health Organization (WHO), and this included 145 deaths. All reported cases had a history of travel to or residence in the following seven countries: Saudi Arabia, United Arab Emirates (UAE), Qatar, Oman, Jordan, Kuwait and Yemen, and the most recent cases were reported from Saudi Arabia and the UAE $(1,2)$. Furthermore, MERS cases have also been reported by the WHO, from countries outside the Arabian Peninsula, such as the United Kingdom, France, Tunisia and Italy, during 2013; and Greece, Egypt, Malaysia, and the United States in 2014 (2). The Iranian Center for Disease Control (CDC) has reported two cases from Iran, (city of Kerman) with one death (5). The MRES$\mathrm{CoV}$ is a notifiable and quarantinable disease and any suspected cases should immediately be reported to the local CDC. The use of standard precautions in conjunction with airborne precautions and contact are recommended for any suspected, probable or confirmed cases $(1,6,7)$. It is important to mention that suspected case is considered as a person with fever and pneumonia or acute respiratory distress syndrome (ARDS) with clinical, radiological, and histopathological evidence of pulmonary parenchymal disease and one of the following items;

A history of residence in, or travel to, the Arabian Peninsula or neighboring countries within 14 days before the onset of illness, or at least one item from the below options:
1- Close contact with a probable or confirmed case within 14 days before onset of disease

2- Being a member of a cluster of patients with ARDS of unknown etiology.

Probable case is considered as a person with an acute febrile respiratory illness with clinical, radiological, and histopathological evidence of pulmonary parenchymal disease, without the possibility of laboratory confirmation for MERS-CoV and a history of close contact with a laboratory-confirmed case. A confirmed case is a patient with laboratory confirmation (RT-PCR) of infection with MERS-CoV.

To increase the likelihood of confirmation of MERS-CoV infection, $C D C$ recommends multiple specimens to be collected from various sites and at different times after symptoms begin. Health-care personnel should collect a nasopharyngeal swab, or pharyngeal swab, sputum, bronchoalveolar lavage, serum, and stool sample or rectal swab $(1,2,6)$. Health care workers who collect specimens should wear gloves, gowns, and use eye and mouth protection during patient care activities that are likely to generate splashes of body fluids, blood and other secretions. Hand washing has an important role in prevention of infection (2, 6-9). People who enter the patients room should wear disposable gowns and gloves and use of a particulate respirator (N95). Also, strict adherence to hand hygiene is very important. People who should be considered as having MERS-CoV and should be tested are $(1,6,7)$ :

1- Individuals with pneumonia and history of residence in, or travel to, the Arabian Peninsula or neighboring countries within 14 days before onset of illness.

2- Individuals with acute respiratory infection and history of contact with those in option 1, or contact with a probable or confirmed case, during the last 14 days.

3-Health care staff with pneumonia, who have been caring for patients with severe acute respiratory infections, particularly patients requiring intensive care, regardless of the place of residence or history of travel, where other causes have not been confirmed.

Copyright (C) 2015, School of Paramedical Sciences, Qazvin University of Medical Sciences. This is an open-access article distributed under the terms of the Creative Commons Attribution-NonCommercial 4.0 International License (http://creativecommons.org/licenses/by-nc/4.0/) which permits copy and redistribute the material just in noncommercial usages, provided the original work is properly cited. 
There is no vaccine or specific treatment for MERS. The patients should be treated as for other severe acute respiratory illnesses. The $\mathrm{CDC}$ recommends that all travelers to countries in or near the Arabian Peninsula must protect themselves from respiratory diseases including MERS$\mathrm{CoV}$ by hand washing often and avoiding contact with people who have an acute respiratory illness. If travelers to countries with MERS, have onset of fever with cough or shortness of breath during their trip or within 14 days of returning to their country, they should seek specific medical care (6-8).

\section{References}

1. Laboratory testing for Middle East respiratory syndrome coronavirus. 2013. Available from: www.who.int/csr/disease/coronavirus_infections/MERS_Lab_recos_16_Sept_2013.pdf.

2. MERS-CoV.. Available from: http://www.medscape.com/viewarticl e/825179_2?nlid=57752_804.
3. Memish ZA, Cotten M, Meyer B, Watson SJ, Alsahafi AJ, Al Rabeeah AA, et al. Human infection with MERS coronavirus after exposure to infected camels, Saudi Arabia, 2013. Emerg Infect Dis. 2014;20(6):1012-5.

4. Chu DK, Poon LL, Gomaa MM, Shehata MM, Perera RA, Abu Zeid D, et al. MERS coronaviruses in dromedary camels, Egypt. Emerg Infect Dis. 2014;20(6):1049-53.

5. Gladstone R. Iran: MERS Virus Reaches Its 20th Country. 2014. Available from: http://www.nytimes.com/2014/05/29/world/middleeast/iran-mers-virus-reaches-its-20th-country.html?_r=0.

6. Bialek SR, Allen D, Alvarado-Ramy F, Arthur R, Balajee A, Bell D, et al. First confirmed cases of Middle East respiratory syndrome coronavirus (MERS-CoV) infection in the United States, updated information on the epidemiology of MERS-CoV infection, and guidance for the public, clinicians, and public health authorities - May 2014. MMWR Morb Mortal Wkly Rep. 2014;63(19):431-6.

7. Karagoz E, Hatipoglu M, Turhan V. Is aerosol-based transmission of Middle East respiratory syndrome coronavirus possible? J Infect Dis. 2014;210(10):1680-1.

8. Zumla A, Hui DS. Infection control and MERS-CoV in health-care workers. Lancet. 2014;383(9932):1869-71.

9. Bouree P. [MERS-CoV: a new virus from Saudi Arabia]. Rev Prat 2014;64(4):457-60. 